\title{
Portion size of energy-dense foods in French and UK adults by BMI status: is there an association between portion size and BMI?
}

\author{
H.L. Rippin ${ }^{1}$, J. Hutchinson ${ }^{1}$, J. Jewell ${ }^{2}$, J.J Breda ${ }^{2}$ and J.E. Cade ${ }^{1}$ \\ ${ }^{1}$ Nutritional Epidemiology Group (NEG), School of Food Science and Nutrition, University of Leeds, Leeds, LS2 9JT \\ and ${ }^{2}$ Division of Noncommunicable Diseases and Promoting Health through the Life-Course, World Health \\ Organization Regional Office for Europe, UN City, Marmorvej 51, 21000 Copenhagen, Denmark.
}

There is no established causal relationship between food portion size (FPS) and obesity, but evidence indicates a link via increased energy intake, particularly from energy-dense foods, suggesting that limiting FPS contributes to reduced energy intake and therefore reduced weight gain ${ }^{(1)}$. FPS is increasing in some energy-dense foods, which may increase intake via the 'portion size effect'. In the current study FPS of commonly consumed energy, fat and sugar-dense foods in French and UK adults are determined by BMI status, and associations between FPS and BMI investigated.

Data for adults aged 19-64y was analysed in two national surveys - the French Étude Individuelle Nationale des Consommations Alimentaires2 (INCA2) collected 2005-2007 via 7-day diary $(\mathrm{n}=2240)$, and the UK National Diet \& Nutrition Survey (NDNS) collected 2008-2014 using 4-day diary $(n=3662)^{(2-4)}$. Commonly consumed energy-dense food groups were split into characteristicbased food subgroups. Means of consumed FPS per eating occasion for normal weight were compared to overweight or obese (OWOB) individuals and regression analysis was adjusted for sex and age to determine associations between BMI as a continuous variable and FPS. Effects of under-reporting were explored.

In the adjusted analyses only $10 \%(n=8 / 78)$ food subgroups had significant associations between FPS and BMI (table 1). Few similarities existed between the countries, though most associations were positive, where OWOB individuals had higher FPS. Under-reporting was higher in the UK, but affected the number and type of associations in both countries.

Table 1. Significant associations between FPS and BMI after adjusting for sex and age.

\begin{tabular}{|c|c|c|c|c|c|c|}
\hline \multirow{2}{*}{$\begin{array}{l}\text { Survey } \\
\text { INCA2 }\end{array}$} & \multirow{2}{*}{$\begin{array}{c}\text { Food Subgroup } \\
\text { Misc. cakes \& patisserie }\end{array}$} & \multirow{2}{*}{$\begin{array}{c}\text { n* } \\
33\end{array}$} & \multirow{2}{*}{$\begin{array}{c}\text { Change in FPS }(\mathrm{g}) \text { per BMI point increase } \\
3 \cdot 1\end{array}$} & \multicolumn{2}{|c|}{$95 \%$ CI (g) } & \multirow{2}{*}{$\frac{\text { Adjusted p-value }}{<0.001}$} \\
\hline & & & & $1 \cdot 5$ & $4 \cdot 7$ & \\
\hline & Chocolate Cake \& Gateau & 397 & $1 \cdot 3$ & $0 \cdot 01$ & $2 \cdot 5$ & $<0.05$ \\
\hline & Dark chocolate & 274 & $1 \cdot 0$ & $0 \cdot 3$ & $1 \cdot 6$ & 0.004 \\
\hline \multirow[t]{5}{*}{ NDNS } & Misc. cakes \& pastries & 78 & $2 \cdot 0$ & $0 \cdot 2$ & $3 \cdot 7$ & $0 \cdot 03$ \\
\hline & Bars \& Slices & 138 & $-0 \cdot 8$ & -1.5 & $0 \cdot 0$ & $0 \cdot 04$ \\
\hline & Fruit Cake \& malt loaf & 95 & 1.7 & $0 \cdot 2$ & $3 \cdot 2$ & 0.03 \\
\hline & High Fat Bar Snacks & 64 & $4 \cdot 1$ & $0 \cdot 2$ & $8 \cdot 0$ & $0 \cdot 04$ \\
\hline & Nuts & 9 & $3 \cdot 3$ & $0 \cdot 7$ & $5 \cdot 9$ & 0.01 \\
\hline
\end{tabular}

*Unweighted

There was limited evidence of links between BMI and FPS in UK and French data in these cross-sectional studies. Future work should explore the relationship between consumed FPS and on-pack suggested serving sizes and overall pack sizes to provide evidence to assist obesity-prevention policy decisions.

1. World Health Organisation (2014) Limiting portion sizes to reduce the risk of childhood overweight and obesity. Geneva: WHO. http://www.who. int/elena/bbc/portion_childhood_obesity/en/ (accessed March 2018).

2. Agence française de sécurité sanitaire des aliments (2009) Étude Individuelle Nationale des Consommations Alimentaires 2 (INCA2) (2006-2007) Rapport Maisons-Alfort: AFSSA.

3. Bates B, Cox L, Nicholson S et al. (2016) National Diet and Nutrition Survey Results from Years 5 and 6 (combined) of the Rolling Programme (2012/2013-2013/2014) London: PHE.

4. Bates B, Lennox A, Prentice A et al. (2014) National Diet and Nutrition Survey: Results from Years 1, 2, 3 and 4 (combined) of the Rolling Programme (2008/2009-2011/2012) London: PHE. 